\title{
Reproductive Behavior of Induced Allotetraploid xChitalpa and In Vitro Embryo Culture of Polyploid Progeny
}

\author{
Richard T. Olsen ${ }^{1}$, Thomas G. Ranney ${ }^{2}$, and Zenaida Viloria ${ }^{3}$ \\ Department of Horticultural Science, Mountain Horticultural Crops Research and Extension Center, \\ North Carolina State University, Fletcher, NC 28732-9244
}

\begin{abstract}
Additional Index words. Catalpa bignonioides, Chilopsis linearis, cytochimera, embryo rescue, flow cytometry, pollen viability, triploid block

Aвstract. $\times$ Chitalpa tashkentensis Elias \& Wisura is a sterile intergeneric hybrid [Catalpa bignonioides Walt. $\times$ Chilopsis linearis (Cav.) Sweet]. To restore fertility in $\times$ Chitalpa the following were evaluated: 1 ) oryzalin as a polyploidization agent, 2) fertility of induced polyploids, and 3) in vitro culture methods for embryo rescue of interploid crosses. Meristems of $\times$ Chitalpa 'Pink Dawn' were submerged in an aqueous solution of $150 \mu \mathrm{M}$ oryzalin for $0,6,12$, or 24 hours and ploidy analyzed via flow cytometry. As treatment duration increased, recovery of diploids decreased as mixoploids and shoot mortality increased. Two tetraploid shoots occurred in the 24-hour treatment. Four tetraploids and two cytochimeras were stabilized in total. Tetraploids flowered sparsely; however, cytochimeras flowered profusely and these were used to study fertility at the tetraploid level. Diploid $\times$ Chitalpa 'Pink Dawn' pollen was essentially nonviable, but cytochimera pollen stained and germinated equal to or greater than pollen of $C$. bignonioides and $C$. linearis 'Bubba'. Cytochimera $\times$ Chitalpa were selfed yielding tetraploid seedlings, crossed with $C$. bignonioides to yield triploids, but failed in reciprocal crosses with $C$. linearis 'Bubba' and 'Burgundy Lace'. To increase recovery of triploids, germination of triploid and tetraploid embryos was investigated, as either intact ovules or excised embryos, on Schenk and Hildebrandt (SH) basal salts supplemented with sucrose at 20,40 , and $80 \mathrm{~g} \cdot \mathrm{L}^{-1}$, presence or absence of $2 \%$ coconut-water, and gibberellic acid $\left(\mathrm{GA}_{3}\right)$ at $0,1,2$, or $4 \mu \mathrm{M}$, and harvested weekly beginning 2 weeks after pollination (WAP). Germination of triploids (cytochimera $\times$ Chitalpa $\times$ diploid $C$. bignonioides) and tetraploids (selfed cytochimera $\times$ Chitalpa) were greatest with excised embryos at 7 WAP on SH supplemented with sucrose at $20 \mathrm{~g} \cdot \mathrm{L}^{-1}$ and $\geq 1 \mu \mathrm{M} \mathrm{GA}$. Germination of triploids (diploid $C$. linearis $x$ cytochimera $\times$ Chitalpa) was $<5 \%$ at 4,5 , or 6 WAP on the same medium as above. Oryzalin effectively induced polyploidy and restored fertility in $\times$ Chitalpa 'Pink Dawn'. Successful crosses between hybrid and parental taxa of different ploidy levels, coupled with embryo culture will facilitate a $\times$ Chitalpa breeding program. Chemical names used: 4(dipropylamino)-3,5-dinitrobenzenesulfonamide (oryzalin).
\end{abstract}

In the early 1960s, F.N. Rusanov, of the Uzbek Academy of Sciences Botanical Garden, Tashkent, Uzbekistan (formerly the Republic of Uzbekistan, U.S.S.R.), made a series of intergeneric crosses between species of catalpa (Catalpa Scop.) and desertwillow (Chilopsis linearis) (Rusanov, 1964). Chilopsis D. Don. is a monotypic genus, sister to Catalpa within the tribe Tecomeae Endl. of the Bignoniaceae Juss. The genera are morphologically similar(Henrickson, 1985), and share the same areolate tetrad pol-

Received for publication 26 Apr. 2006. Accepted for publication 20 Aug. 2006. This research was funded, in part, by the North Carolina Agricultural Research Service (NCARS), Raleigh, NC 27695-7643; North Carolina Association of Nurserymen, Inc., 969 Trinity Road, Raleigh, NC 27607; and J. Frank Schmidt Family Charitable Foundation, Boring, OR 97009. Use of trade names in this publication does not imply endorsement by the NCARS of products named nor criticism of similar ones not mentioned. We gratefully acknowledge Dawn Stover and David Creech, Mast Arboretum, Stephen F. Austin University, Nacogdoches, TX 75962; and Garry McDonald and Mike Arnold, Department of Horticultural Sciences, Texas A\&M University, College Station, TX 77843, for providing plants and cuttings of Chilopsis. Technical assistance of Thomas Eaker, Joel Mowrey, Nathan Lynch, and staff of the Mountain Horticultural Crops Research and Extension Center is greatly appreciated. We thank William Swallow and Sandy Donaghy for statistical assistance. From a dissertation submitted by R.T.O. in partial fulfillment of the requirements for the $\mathrm{PhD}$ degree.

${ }^{1}$ Corresponding author. Current address: Floral and Nursery Plants Research Unit, USDA-ARS, U.S. National Arboretum, 3501 New York Ave. NE, Washington, D.C. 20002; e-mail: Richard.Olsen@ars.usda.gov

${ }^{2}$ Professor.

${ }^{3}$ Visiting scientist. Home institution: La Universidad del Zulia, Facultad de Agronomia, Apdo. 15205, Maracaibo 4005, Estado Zulia, Venezuela. len type (Gentry and Tomb, 1979) and base chromosome number $(n=20)$ (Goldblatt and Gentry, 1979), and are both gametophytic self-incompatible (Petersen et al., 1982; Stephenson and Thomas, 1977). Reciprocal crosses were made between several Catalpa spp. and $C$. linearis, resulting, ultimately, in describing and naming of one new hybrid species: $\times$ Chitalpa tashkentensis, an intergeneric hybrid between Catalpa bignonioides and C. linearis (Elias and Wisura, 1991). According to Elias and Wisura, who translated from Rusanov (1971), the hybrids were sterile with pollen grains developing abnormally into pentads and hexads which contain uninuclear pollen and normally degenerate.

Sterility in wide hybrids is often a result of abnormal meiotic pairing between the divergent parental chromosomes, leading to both chromosomal and genic imbalances during chromosome segregation (Hadley and Openshaw, 1980; Rieseberg and Carney, 1998) and ultimately, abnormal or abortive gamete development. Inducing polyploidy is a viable method for improving meiotic pairing and restoring fertility in wide crosses (Hadley and Openshaw, 1980; Sanford, 1983). Mitotic inhibiting chemicals such as colchicine and the dinitroaniline herbicide oryzalin inhibit formation of the spindle apparatus during mitosis, allowing replication of DNA but preventing cell division (Bajer and Molè-Bajer, 1986; Bartels and Hilton, 1973; Vaughn and Lehnen, 1991). Several in vitro studies involving diverse plant genera have shown that oryzalin is more efficient than colchicine at inducing polyploidy (Ramulu et al., 1991; Tosca et al., 1995; Väinölä, 2000). Oryzalin uptake in plant tissues is a rapid, nonactive process; its extremely 
lipophilic nature facilitates passive absorption and diffusion into lipid components of cellular membranes with little translocation (Upadhyaya and Noodèn, 1977, 1980). In actively dividing cells, oryzalin binds to tubulin heterodimers, preventing polymerization of both mitotic spindles and cortical microtubules, thus leading to polyploid cells (Morejohn et al., 1987; Vaughn and Lehnen, 1991).

Induction of polyploidy in interspecific or intergeneric hybrids results in duplication of the two genomes present in the hybrid and formation of an allopolyploid. The degree of fertility in the ensuing allopolyploid is related to the amount of divergence between the genomes of the parental taxa and the degree of homologous vs. homoeologous pairing (Gottschalk, 1978; Levin, 2002). Meiotic pairing may or may not be fully restored in allopolyploids; however, they normally exhibit improved fertility over the original wide hybrid. This allows for continued introgression of desired genes into the cultivated gene pool. The technique has been used for the overall genetic improvement of a number of important agronomic crops, such as cotton [Gossypium L. (Brubaker et al., 1999)], sunflowers [Helianthus L. (Jan and Chandler, 1989)], and various small fruit crops (Sanford, 1983), but only a few ornamental nursery crops, a notable exception being roses [Rosa L. (Ma et al., 1997)]. For cultivated crops where germplasm encompasses several ploidy levels, such as potato [Solanum tuberosum L. (Jackson and Hanneman, 1999)], cotton (Brubaker et al., 1999), and roses (Cole and Melton, 1986; Ma et al., 1997), inducing polyploids not only restores fertility, but facilitates hybridization with other taxa at the same ploidy level (intraploid). For predominantly diploid crops, the increase in ploidy may represent a hindrance as backcrosses to desirable parental taxa involve crossing between ploidy levels (interploid). The success of interploid crosses depends, in part, on the maternal:paternal genomic ratio in the developing endosperm, with crosses that violate a 2:1 maternal : paternal ratio often resulting in abnormal or abortive embryos according to the endosperm balance number theory (EBN) (Carputo et al., 1999; Johnston et al., 1980; Sanford, 1983).

Although fertile interspecific hybrids have been reported in catalpa (Jones and Filley, 1920; Sargent, 1889; Smith, 1941), the intergeneric hybrid between Chilopsis and Catalpa, $\times$ C.tashkentensis, is sterile (Elias and Wisura, 1991). Sterility of the bi-generic cross prevents use of the hybrid in breeding programs to further combine desirable traits such as improved disease resistance, greater cold hardiness, and novel flower and foliage characteristics. Therefore, to initiate a breeding program for $\times$ Chitalpa our objectives were to 1) evaluate the efficacy of oryzalin to induce polyploidy in vegetative meristems of $\times$ Chitalpa, 2) evaluate fertility and crossability of induced allotetraploids, and 3) develop in vitro methods for recovering progeny from interploid crosses between $\times$ Chitalpa, $C$. bignonioides, and $C$. linearis.

\section{Materials and Methods}

INDUCING POLYPLOIDY. Thirty-two plants of $\times C$. tashkentenis 'Pink Dawn' growing in 1-L containers were selected from stock material growing at the Mountain Horticultural Crops Research Station (MHCREC), Fletcher, N.C., in June 2002. Plants were grown in a substrate of 3 pine bark : 1 peat (by volume) amended with $2.8 \mathrm{~kg} \cdot \mathrm{m}^{-3}$ dolomitic limestone and $0.5 \mathrm{~kg} \cdot \mathrm{m}^{-3}$ Micromax micronutrients (The Scotts Co., Marysville, Ohio). Plants were transported to the laboratory and each plant was pruned to three actively growing shoots and terminal leaves removed to expose apical meristems. Apical meristems were submerged in beakers containing a saturated aqueous solution of $150 \mu \mathrm{M}$ oryzalin $\left[0.004 \% \mathrm{v} / \mathrm{v}\right.$ Surflan ${ }^{\circledR}$ (Dow AgroSciences, Indianapolis)] for one of four treatment durations: 0, 6, 12, or $24 \mathrm{~h}$. After treatment, plants were moved to the greenhouse, repotted into 7.6-L containers with the same substrate, and top-dressed with $20 \mathrm{~g} / \mathrm{container}$ 17N-7.4P-14.1K Multicote controlled-release fertilizer (Vicksburg Chemical Co., Vicksburg, Miss.).

After growth resumed, DNA content and ploidy levels were determined via flow cytometry (de Laat et al., 1987; Doležel, 1991; Galbraith et al., 1983). Nuclei isolation and staining followed the protocols provided by Partec (Partec GmbH, Münster, Germany). Approximately $0.5 \mathrm{~cm}^{2}$ of newly expanded leaf tissue was chopped with a double-sided razor blade in a petri dish containing $400 \mu \mathrm{L}$ of extraction buffer (CyStain UV Precise P; Partec). The suspension was filtered through 50- $\mu$ m nylon mesh and nuclei were stained using $1.6 \mathrm{~mL}$ staining buffer containing 4',6-diamidino-2-phenylindole (DAPI) (CyStain UV Precise P). The suspension was analyzed using a flow cytometer with fluorescence excitation provided by a mercury arc lamp (PA-I Ploidy Analyzer, Partec). The mean fluorescence of each sample was compared with diploid $\times C$. tashkentenis 'Pink Dawn' and an internal standard with a known nuclear DNA content (2C) [Pisum sativum L. 'Ctirad', 2C =9.09 pg; (Doležel et al., 1998)]. A minimum of 4500 nuclei were analyzed to calculate the ratio of sample peak to the internal standard for determining nuclear DNA content $[2 \mathrm{C} \mathrm{pg}=($ sample peak/internal standard peak $) \times$ $9.09 \mathrm{pg}$ ]. Sample ploidy levels were calculated by dividing sample nuclear DNA content by that of diploid $\times C$. tashkentenis 'Pink Dawn' [ploidy $=$ sample $2 \mathrm{Cpg} / 2 \mathrm{C} \times C$. tashkentenis 'Pink Dawn' pg]. Peaks used for calculating nuclear DNA content and ploidy levels had coefficients of variation (Cvs) $\leq 8 \%$.

The experimental design was completely randomized with eight single-plant replicates and three sub-samples (shoots) per plant. Oryzalin efficacy was analyzed using nonlinear and linear regression (PROC NLIN and PROC GLM, SAS version 8.02; SAS Institute Inc., Cary, N.C.). After initial treatments and testing, mixoploids and tetraploids were cut back to the point of treatment, forcing new shoots from axillary buds. Ploidy levels for new shoots were determined to chart the stability of the original mixoploids or tetraploids. This cycle was repeated. Shoots were considered stabilized when every leaf on a stem and subsequent shoots that arose from the axils exhibited the same ploidy level. Stem cuttings from stabilized shoots were rooted and grown in a greenhouse under the same conditions as the original plants.

Pollen viability. Diploid $(2 x)$, cytochimera $(2 x+4 x)$ and tetraploid $(4 x) \times C$. tashkentenis 'Pink Dawn', identified from oryzalin treatments, were grown along with $C$. linearis 'Bubba' to flowering in greenhouses at MHCREC. All pollen for viability tests were collected at anthesis from greenhouse plants with the exception of $C$. bignonioides, which was collected from naturalized trees growing near the research station. Pollen viability was quantified using pollen staining and pollen germination tests conducted during 2003 and repeated in 2004. Pollen grains were treated using Müntzing's stain, 1 acetocarmine (1\%): 1 glycerol, for $3 \mathrm{~h}$. Stained pollen grains were scored as viable. Pollen germination was quantified utilizing spot tests with Brewbaker-Kwack media (Brewbaker and Kwack, 1963) supplemented with sucrose. A $100-\mu \mathrm{L}$ drop of media was placed in the bottom of a $5-\mathrm{mL}$ petri dish and a dehisced anther swirled in the drop to release pollen grains. A moistened piece of filter paper was placed in the lid of the petri dish, and the petri dish covered and incubated at room 
temperature $\left(23^{\circ} \mathrm{C}\right)$. Pollen grains with pollen tubes greater than one-half the diameter of the pollen grain after $8 \mathrm{~h}$ were scored as germinated. In 2003, consistent pollen germination occurred at $10 \%$ sucrose. In 2004, pollen germination was sporadic at $10 \%$, so sucrose concentration was increased to $15 \%$. Pollen staining and germination were observed using a compound light microscope (Micromaster; Fisher Scientific, Pittsburgh) under $\times 100$ and $\times 400$ magnifications. Each pollen replicate contained eight subsamples, with $\geq 100$ pollen grains. Each test was a completely randomized design with 2 replicates (years) $\times 4$ treatments (taxa) $\times 8$ subsamples. Data were analyzed using PROC GLM (SAS) and means compared using Tukey's honestly significant difference test with the experimentwise Type I error rate controlled at $\alpha=0.05$.

Crossability studies. Female fertility was assessed using the same plant material as for the pollen viability tests, with the addition of $C$. linearis 'Burgundy Lace'. For all crosses, flowers were emasculated prior to anthesis. Stamens were collected, dried overnight at $5{ }^{\circ} \mathrm{C}$ using indicator Drierite (Drierite, Xenia, Ohio), and stored at $5^{\circ} \mathrm{C}$ for use in subsequent crosses. Stigmas were receptive to pollen when stigma lobes separated, generally the afternoon after emasculation. Pollen was applied to stigmas using fine brushes. Catalpa spp. and C. linearis stigmas are haptonastic, and close permanently when pollinated with viable pollen grains (Newcombe, 1922; Petersen et al., 1982); ×Chitalpa stigmas responded in a similar manner (personal observation). The number of pollinations varied depending on the availability of flowers on female parents. Percent fruit set, average seed per fruit, and seed germination were recorded for each cross. All seed were counted at maturity, even seeds that appeared to contain aborted embryos, so as to elucidate triploid blocks. Seeds were surface-sown on a substrate of 1 peat: 1 vermiculite (by volume) in flats and misted regularly until germination occurred in 1 to 4 weeks. Crosses were conducted in the greenhouses during each growing season from 2003-05.

IN VITRO OVULE AND EMBRYo RESCUE. During summers 2004 and 2005, a series of experiments were designed using the above crosses to investigate optimal timing and medium components for ovule and embryo culture of $\times$ Chitalpa hybrids to facilitate recovery of triploids $(3 x)$. Fruit collection and sterilization were the same for each experiment. Fruit were removed and brought to the laboratory, washed in dish-soap and water, stirring frequently for 5 to $10 \mathrm{~min}$. Fruit were rinsed with running water and transferred to $70 \%$ ethanol for $2 \mathrm{~min}$, rinsed with sterile distilled water, and further sterilized by submersion in a solution of $1.05 \%$ sodium hypochlorite with 2 to 3 drops of polyethylene-20-sorbitan monolaurate (Tween 20; Fisher Scientific, Fair Lawn, N.J.) for $30 \mathrm{~min}$. Fruit were rinsed three times with sterile distilled water and ovules and embryos excised under aseptic conditions. Fruit collection and sterilization were the same for each experiment. The basic medium for each experiment included Schenk and Hildebrandt (SH) salts (S6765; Sigma-Aldrich Co., St. Louis) and vitamins (Beyl, 2000), $\mathrm{pH}$ adjusted to 5.7 prior to autoclaving, and solidified with agar at $7 \mathrm{~g} \cdot \mathrm{L}^{-1}$ (A6686; Sigma-Aldrich). Twenty-five-millimeter petri dishes were used with $\sim 15 \mathrm{~mL}$ of medium added to each dish. Cultures were maintained at $25^{\circ} \mathrm{C}$ under a 16 -h photoperiod of $75 \mu \mathrm{mol} \cdot \mathrm{s}^{-1} \cdot \mathrm{m}^{-2}$ photosynthetic active radiation $(P A R)$ provided by cool-white fluorescent lamps.

Expт. 1. To test the effects of harvest date and the medium supplements coconut-water and sucrose on germination of triploid $(3 x)$ and tetraploid ( $4 x$ ) embryos, fruit were collected at 2, 3, 4, 5 , or 6 weeks after pollination (WAP) from $(\times$ C. tashkentenis $2 x$
$+4 x) \times C$. bignonioides $2 x$ and selfed $\times C$. tashkentenis $2 x+4 x$, respectively. Intact ovules were excised and plated in petri dishes containing SH medium, with or without coconut-water $(2 \%)$ (C5915; Sigma-Aldrich), and one of three sucrose concentrations $\left(20,40\right.$, or $\left.80 \mathrm{~g} \cdot \mathrm{L}^{-1}\right)$. Experimental design was a split plot with 2 (ploidy) $\times 2$ (coconut-water $) \times 3$ (sucrose) factorial main plot with WAP as the subplot, and five replicates (petri dishes) with six subsamples (ovules) per replicate and treatment combination. Germination percentage for each treatment combination was recorded 6 weeks after plating.

ExPT. 2. At 6 WAP, expanding embryos were apparent with the naked eye, so a new study was initiated to investigate the effect of coconut-water and sucrose concentration on excised embryos at this single harvest date. Embryos were harvested from the same crosses and factorial treatment combinations as in Expt. 1 , but with four replicates. Embryo germination was recorded 6 weeks after plating.

ExpT. 3. The effect of $\mathrm{GA}_{3}$ in promoting germination of embryos was tested using embryos from both crosses at 7 WAP. Embryos were excised and plated in $\mathrm{SH}$ medium supplemented with sucrose at $20 \mathrm{~g} \cdot \mathrm{L}^{-1}$ and $0,1,2$, or $4 \mu \mathrm{M} \mathrm{GA}$. The $\mathrm{GA}_{3}$ treatment consisted of six replicates (petri dishes) with six subsamples (embryos) per dish. Embryo germination was recorded 4 weeks after plating.

ExpT. 4. To test the effect of harvest date on in vitro germination of $3 x$ embryos from $2 x \times(2 x+4 x)$ cross, fruit were collected at $3,4,5,6$, or 7 WAP from $C$. linearis 'Bubba' and 'Burgundy Lace' as $2 x$ female parents and cytochimeric $\times C$. tashkentenis $(2 x+4 x)$ as the male parent. Ovules were excised, torn in half longitudinally to expose the developing embryo, and plated on SH medium supplemented with sucrose at $20 \mathrm{~g} \cdot \mathrm{L}^{-1}$ and $1 \mu \mathrm{M}$ $\mathrm{GA}_{3}$. For each harvest date there were six replicates (petri dishes) with eight subsamples (embryos) per replicate. Percentages of embryos producing callus and germinating were recorded 6 weeks after plating. Callus production was recorded in this experiment to note which treatments to pursue in future studies of somatic embryogenesis or shoot organogenesis from $3 x$ embryonic callus. Data for each ovule and embryo culture experiment were analyzed separately according to individual experimental designs using PROC ANOVA (SAS) with the appropriate error term for F tests.

\section{Results}

INDUCING POLYPLOIDY. Duration of oryzalin treatment had a significant effect on the percentage of diploids, mixoploids, and mortality of shoot meristems (Fig. 1). As treatment duration increased, the percentage of diploids decreased exponentially. Reduction in diploid shoots was concurrent with an increase in both mixoploids and shoot mortality. The percentage of mixoploids demonstrated a quadratic response, increasing up to the 12-h treatment. In the 24-h treatment, decreases in percent diploid and mixoploid shoots were the result of increases in shoot mortality and induction of two tetraploid shoots. The absence of tetraploid shoots in treatments other than the 24-h duration precluded regression analysis and $t$ tests for comparing this treatment with all other durations.

Flow cytometry provided a rapid and reliable screen for determining ploidy levels of treated shoots (Fig. 2A-B and D). DNA content for diploid $(2 n=2 x=20)$ and tetraploid $(2 n=4 x$ $=40) \times C$. tashkentensis were $2.27 \pm 0.2 \mathrm{pg}$ and $4.59 \pm 0.2 \mathrm{pg}$, respectively. Of the original 96 shoots treated, 34\% (33 of 96) 


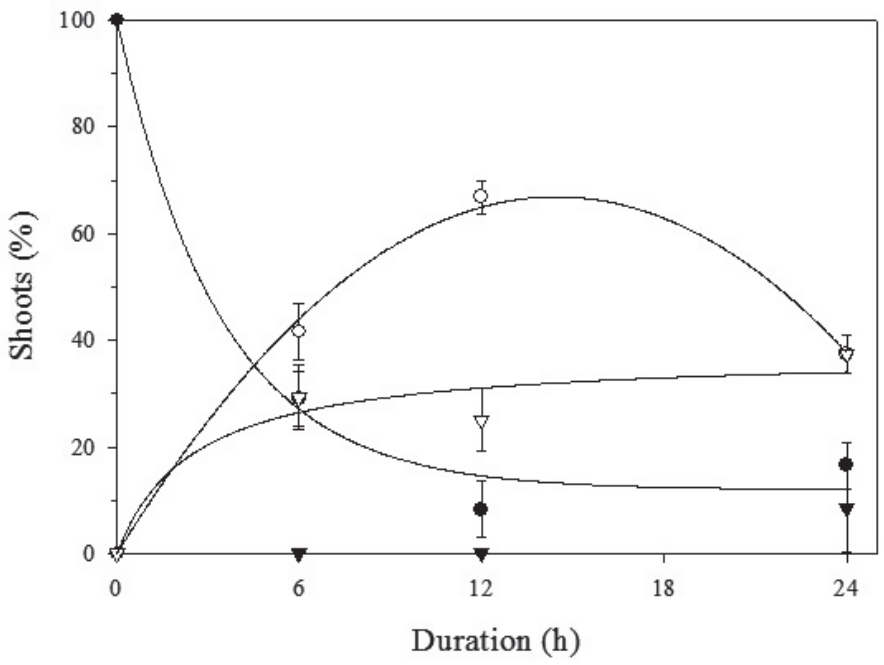

Fig. 1. Efficacy of a $150 \mu \mathrm{M}$ oryzalin solution for inducing polyploidy in actively growing shoot meristems of $\times$ Chitalpa tashkentensis 'Pink Dawn'. Symbols represent mean percentage of diploid $(\mathbf{O})$, mixoploid $(\square)$ and tetraploid $(\nabla)$ shoots and shoot mortality $(\nabla)$ as a function of treatment duration \pm 1 SE. Solid lines represent curves fitted using linear and nonlinear regression analysis: diploids $(\bigcirc)=12.0+88.17[-0.29$ (duration) $], F$ value $=56.14, P<0.0001 ;$ mixoploid $(\square)=9.26$ (duration) -0.32 (duration) $)^{2}, r^{2}=0.79$; dead shoots $(\nabla)=37.57$ (duration) $/(2.52+$ duration $), \mathrm{F}$ value $=19.28, P<0.0001$. Two solid tetraploids ( $\boldsymbol{\nabla})$ were found at the 24 -h treatment, which was not sufficient for proper regression analysis. Each treatment consisted of eight single-plant replicates and three subsamples (shoots) per replicate.

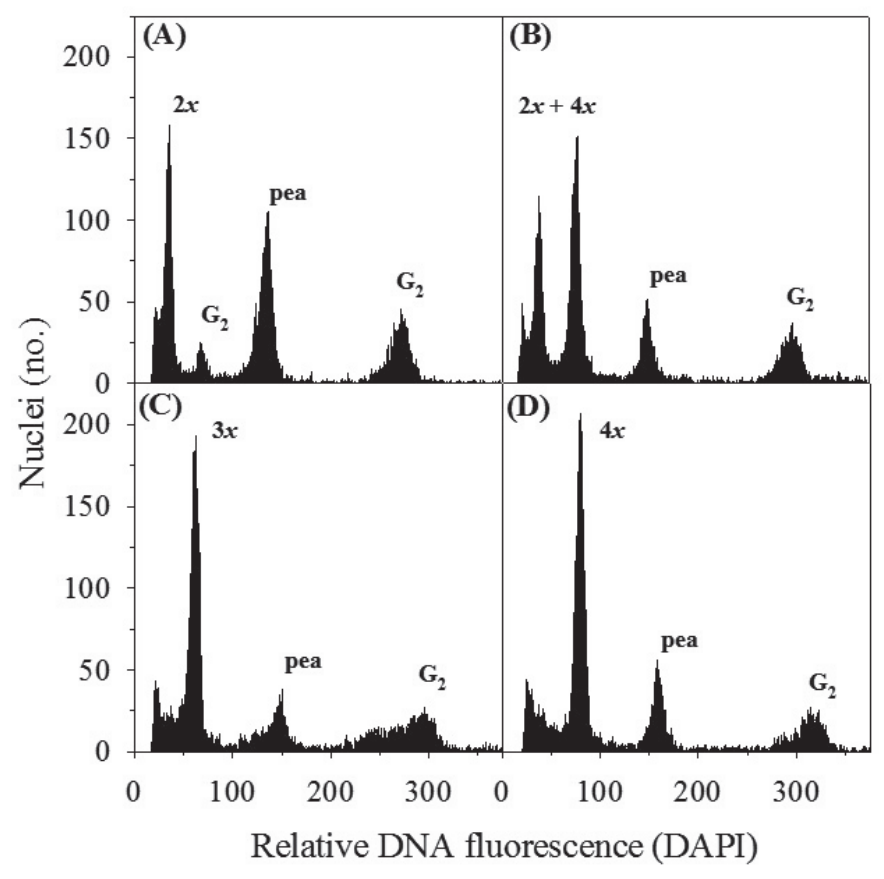

Fig. 2. Flow cytometry histograms of $\times$ Chitalpa tashkentensis $(\mathbf{A})$ diploid, (B) cytochimera, $(\mathbf{C})$ triploid, and (D) tetraploid plants. Relative DNA content and ploidy levels were calculated from the ratio of sample peaks to that of the internal standard, pea (Pisum sativum 'Ctirad', 2C DNA content $=9.09 \mathrm{pg}$ ). Mode of diploid (A) $2 x$ peak $=35, \mathrm{G}_{2}=67$, pea $=136$; cytochimera $(\mathbf{B}) 2 x$ peak $=38,4 x$ peak $=77$, pea $=149 ;$ triploid $(\mathbf{C}) 3 x$ peak $=62$, pea $=150$; and tetraploid (D) $4 x$ peak $=80$, pea $=158$. Peaks beyond fluorescent channel 200 represent cell cycling $\left(\mathrm{G}_{2}\right)$ and sticky nuclei of the internal standard. Extracted nuclei were stained using 4',6-diamidino-2-phenylindole (DAPI). were mixoploids and $2 \%$ ( 2 of 96 ) were tetraploids. These shoots were cut back to recover additional tetraploids from mixoploids or to ensure stability of non-chimeric tetraploids. After removing terminal shoots, new axillary shoots were screened for ploidy level. Of the original mixoploids, $45 \%$ (15 of 33) reverted back to diploids, $45 \%$ (15 of 33) remained mixoploid, and 9\% (3 of 33) stabilized to tetraploids (data not shown). Of the two shoots identified as non-chimeric tetraploids from the original 24-h treatment, one reverted to the diploid state. The remaining mixoploids and tetraploids were cut back a second time, again, in an effort to further isolate stable tetraploid shoots. After the second cut, $40 \%$ ( 6 of 15 ) of the mixoploids reverted to diploid shoots. However, a similar percent of shoots stabilized to tetraploids as in the first cut, $13 \%$ ( 2 of 15). One of the three tetraploids from the first cut-back reverted to a mixoploid and thus must have contained a few diploid cells. Ultimately, four shoots of the original treated meristems stabilized to tetraploid shoots: three stabilized from mixoploids and one induced directly from a diploid to a tetraploid (Fig. 2D). Of the remaining mixoploids, two stabilized as cytochimeras $(2 x+4 x)$ (Fig. 2B). Flow cytometry of stamens and petals of the cytochimeras indicated these tissues maintained the cytochimeric condition of the shoots $(2 x+4 x)$. Likewise, dehiscing anthers contained copious, bright yellow pollen, suggesting the L-II histogenic layer was tetraploid in these cytochimeras.

Pollen viabiLity. Induced tetraploid plants flowered sporadically, so the stable cytochimeras, which flowered regularly, were used for pollen viability tests. There was a significant interaction between year and pollen germination $(\mathrm{F}$ value $=2.51 ; P=0.052)$ as a result of moderate increases in pollen germination for all taxa except $2 x \times$ Chitalpa in 2004 with $15 \%$ sucrose (data not shown). The random effect of year is not repeatable, and since rankings of germination percentages between taxa did not change, the data for the 2 years were combined for analysis of variance (ANOVA) [PROC GLM, TEST $\mathrm{h}=$ taxa $\mathrm{e}=$ year (treatment)]. There was a significant effect due to taxa on pollen staining $(\mathrm{F}$ value $=16503$; $P<0.0001)$ and pollen germination ( $\mathrm{F}$ value $=43.8 ; P=0.0016)$. Pollen of diploid $\times C$. tashkentenis 'Pink Dawn' was essentially nonviable, with almost zero percent pollen staining and germination (Table 1). Pollen of cytochimera $\times C$. tashkentenis 'Pink Dawn' were highly viable, staining and germinating equal to, or greater than, the representative parental taxa $C$. bignonioides and C. linearis 'Bubba' (Table 1).

Crossability studies. Controlled crosses from 2003-05 and resultant fruit set, average seed per fruit, and percent seed germination are presented in Table 2 . Diploid $\times C$. tashkentenis 'Pink

Table 1 . Pollen viability tests for diploid $(2 x)$ and cytochimeric $(2 x+4 x)$ $\times$ Chitalpa tashkentensis 'Pink Dawn' and representative diploid parental taxa, Catalpa bignonioides and Chilopsis linearis 'Bubba'.

\begin{tabular}{llcc}
\hline & \multicolumn{3}{c}{ Pollen viability tests } \\
\cline { 2 - 4 } Taxa & Ploidy & Staining & Germination \\
\hline C. bignonioides & $(\%)$ \\
C. linearis 'Bubba' & $2 x$ & $98.0 \mathrm{a}^{\mathrm{y}}$ & $62.3 \mathrm{~b}$ \\
$\times$ C. tashkentensis 'Pink Dawn' & $2 x$ & $94.9 \mathrm{~b}$ & $73.8 \mathrm{ab}$ \\
$\times$ C. tashkentensis 'Pink Dawn' & $2 x+4 x$ & $0.8 \mathrm{c}$ & $0.04 \mathrm{c}$ \\
\end{tabular}

${ }^{2}$ Means are $n=2$ with eight subsamples per replicate and 100 pollen grains counted per subsample for each test.

yMean separation within columns by Tukey's $\mathrm{HSD}_{0.05}$. 
Table 2. Fruit set and seed germination for controlled pollinations between diploid $(2 x)$, cytochimera $(2 x+4 x)$ and tetraploid $(4 x) \times C h i t a l p a$ tashkentensis 'Pink Dawn' and representative diploid parental taxa Catalpa and Chilopsis.

\begin{tabular}{|c|c|c|c|c|c|c|}
\hline \multirow[b]{3}{*}{ Maternal parent } & \multirow[b]{3}{*}{ Pollen source } & \multirow{3}{*}{$\begin{array}{l}\text { Pollinations } \\
\text { (no.) }\end{array}$} & & & \multicolumn{2}{|c|}{ Seed } \\
\hline & & & \multicolumn{2}{|c|}{ Fruit set ${ }^{z}$} & \multirow{2}{*}{$\begin{array}{l}\text { Avg per } \\
\text { fruit (no.) }{ }^{y}\end{array}$} & \multirow{2}{*}{$\begin{array}{c}\text { Germination } \\
(\%)\end{array}$} \\
\hline & & & (no.) & $(\%)$ & & \\
\hline \multirow{3}{*}{$\times C$. tashkentensis 'Pink Dawn' $2 x$} & selfed & 459 & 0 & 0 & --- & --- \\
\hline & Catalpa bignonioides $2 x$ & 619 & 0 & 0 & --- & --- \\
\hline & Chilopsis linearis 'Bubba' $2 x$ & 129 & 0 & 0 & --- & --- \\
\hline \multirow[t]{3}{*}{$\times C$. tashkentensis 'Pink Dawn' $2 x+4 x$} & selfed & 581 & 118 & 20.3 & 50.5 & 80.7 \\
\hline & C. bignonioides $2 x$ & 1390 & 229 & 16.5 & 94.1 & 19.5 \\
\hline & C. linearis 'Bubba' $2 x$ & 243 & 2 & 0.8 & 60.0 & 0.0 \\
\hline$\times$ C. tashkentensis 'Pink Dawn' $4 x$ & C. linearis 'Bubba' $2 x$ & 43 & 0 & 0 & --- & --- \\
\hline \multirow[t]{3}{*}{ C. linearis 'Bubba' $2 x$} & $\times$ C. tashkentensis 'Pink Dawn' $2 x$ & 103 & 0 & 0 & --- & --- \\
\hline & $\times C$. tashkentensis 'Pink Dawn' $2 x+4 \mathrm{x}$ & 329 & 42 & 12.8 & 28.0 & $0.17 x$ \\
\hline & $\times$ C. tashkentensis 'Pink Dawn' $4 \mathrm{x}$ & 57 & 12 & 21.1 & 42.7 & $0.01^{x}$ \\
\hline \multirow[t]{2}{*}{ C. linearis 'Burgundy Lace' $2 x$} & C. linearis 'Bubba' $2 x$ & 53 & 12 & 22.6 & 35.8 & 29.3 \\
\hline & $\times C$. tashkentensis 'Pink Dawn' $2 x+4 x$ & 80 & 11 & 13.7 & 112.3 & $0.32^{x}$ \\
\hline
\end{tabular}

Includes immature fruit harvested for in vitro ovule and embryo experiments.

yAverage seed per fruit harvested at maturity (15 weeks after pollination), includes fully developed seeds with aborted embryos.

xFlow cytometry indicated these seedlings were diploid.

Dawn' failed to initiate fruit when self-pollinated, pollinated with C. bignonioides or $C$. linearis 'Bubba', or when used to pollinate C. linearis 'Bubba'. However, our cytochimera $\times$ C. tashkentenis 'Pink Dawn' was both male and female fertile, with fruit and viable seed developing when selfed or pollinated with $C$. bignonioides. Selfed crosses yielded 50.5 seeds per fruit which germinated at $80.7 \%$. Seedlings were tested via flow cytometry and found to be tetraploid. Cytochimeric $\times C$. tashkentenis 'Pink Dawn' $\mathrm{x}$ Catalpa bignonioides resulted in $16.5 \%$ fruit set, 94.1 seeds per fruit, and $19.5 \%$ germination. Flow cytometry of these seedlings showed that nearly all were triploids (Fig. 2C), although a few diploids and tetraploids were found (data not shown), apparently the result of the rare production of a viable haploid $(n=1 x)$ egg cells in the cytochimera (for diploid seedlings) and unreduced pollen ( $n=2 x$ ) from $C$. bignonioides (for tetraploid seedlings). No viable seed formed when the cytochimera or tetraploid $\times C$. tashkentenis 'Pink Dawn' were pollinated with diploid C. linearis 'Bubba'. The reciprocal cross, $C$. linearis 'Bubba' $\mathrm{x}$ tetraploid $\times$ C. tashkentenis 'Pink Dawn', resulted in $21.1 \%$ fruit set, 42.7 seeds per fruit, but essentially no seed germination $(0.01 \%)$ (Table 2 ). The seedling of the one seed that germinated was found to be diploid (data not shown). Similar seed germination results occurred when $C$. linearis 'Bubba' or $C$. linearis 'Burgundy Lace' were pollinated with cytochimera $\times C$. tashkentenis 'Pink Dawn': $12.8 \%$ fruit set, 28.0 seeds per fruit, and $0 \%$ germination and $13.7 \%$ fruit set, 112.3 seeds per fruit, and $0.3 \%$ germination (all diploid), respectively. Chilopsis linearis 'Burgundy Lace' $\mathrm{x}$ 'Bubba' crosses resulted in 22.6\% fruit set, 35.8 seeds per fruit, and $29.3 \%$ seed germination (Table 2).

IN VITRO OVULE AND EMBRYo RESCUE. Fruit from successful pollinations grew rapidly in length up to $7 \mathrm{WAP}$, reaching $25 \mathrm{~cm}$ or more, and then leveled off until mature at 14-15 WAP (data not shown). Embryos were first visible with the naked eye at 6 WAP and continued to grow, as measured transversally from cotyledon tip to tip, until 11 WAP. Mature embryos from viable crosses were between 4 and $9 \mathrm{~mm}$ (data not shown).

Expт. 1. No ovules germinated for either cross at 2, 3, or 4 WAP or in the sucrose treatments of $80 \mathrm{~g} \cdot \mathrm{L}^{-1}$ (data not shown). Coconut-water treatment was not significant in combined ANOVA analysis, so this treatment was excluded from the final ANOVA for main plot factors [PROC GLM, TEST $h=$ ploidylsucrose $e=r e p$ (ploidy $\times$ sucrose)]. The main plot factor ploidy was significant (F value $=48.38, P<0.0001$ ) as well as the interaction between ploidy $\times$ sucrose $\times$ WAP $(\mathrm{F}$ value $=13.9, P=0.0005)$ so data are presented for each ploidy level, sucrose, and WAP (Table 3 ). Triploid $(3 x)$ ovules germinated only in the 6 WAP and sucrose treatment of $20 \mathrm{~g} \cdot \mathrm{L}^{-1}$. Tetraploid $(4 x)$ ovules germinated at both 5 and 6 WAP and both levels of sucrose. At 5 WAP, highest germination of $4 x$ ovules (30\%) occurred in the sucrose treatment of 40 $\mathrm{g} \cdot \mathrm{L}^{-1}$. At $6 \mathrm{WAP}$, there was a reversal, with greatest germination of $4 x$ ovules $(25 \%)$ in sucrose at $20 \mathrm{~g} \cdot \mathrm{L}^{-1}$. Ovules germinating in the presence of coconut-water had constricted, thickened roots with little secondary root development.

EXPT. 2. Analysis of variance revealed a significant sucrose main effect (F value $=10.07, P=0.0003)$ and coconut-water $\times$ ploidy interaction $(\mathrm{F}$ value $=6.39, P=0.016)$ on germination of excised embryos at 6 WAP. Sucrose was partitioned into linear and lack of fit to linear components, with a significant linear effect ( $\mathrm{F}$ value $=18.21, P=0.001)$. Within a ploidy level, percent germination decreased linearly as sucrose concentration increased (Table 4). For $3 x$ embryos, coconut-water had no effect on germination ( $8.3 \%$ vs. $7.0 \%$, absent vs. present, respectively). The presence of

Table 3. In vitro germination for triploid $(3 x)$ and tetraploid $(4 x) \times C h i$ talpa ovules from $\times$ Chitalpa tashkentensis 'Pink Dawn' $(2 x+4 x) \mathrm{x}$ Catalpa bignonioides $(2 x)$ harvested 5 and 6 weeks after pollination (WAP) and plated at one of two sucrose concentrations.

\begin{tabular}{lccc}
\hline $\begin{array}{l}\text { Embryo } \\
\text { ploidy }\end{array}$ & $\begin{array}{c}\text { Sucrose }^{\mathrm{z}} \\
\left(\mathrm{g} \cdot \mathrm{L}^{-1}\right)\end{array}$ & \multicolumn{2}{c}{ Germination $(\%)$} \\
\cline { 3 - 4 } & 20 & 0.0 & $6 \mathrm{WAP}$ \\
\hline $3 x$ & 40 & 0.0 & $0.0 \mathrm{~b} \mathrm{a}^{\mathrm{y}}$ \\
$4 x$ & 20 & $5.0 \mathrm{~b}$ & $25.0 \mathrm{a}$ \\
& 40 & $30.0 \mathrm{a}$ & $13.4 \mathrm{~b}$
\end{tabular}

${ }^{z}$ Schenk and Hildebrandt basal salts and vitamins supplemented with sucrose as indicated, $0.7 \%$ agar and $\mathrm{pH}$ adjusted to 5.7.

yWithin a ploidy level and WAP, mean $(n=5)$ germination between sucrose treatments followed by the same letter are not significantly different according to F tests at $P<0.05$. 
Table 4. Effect of coconut-water and sucrose concentration on germination of $\times$ Chitalpa embryos from $\times$ Chitalpa tashkentensis ${ }^{\prime}$ Pink Dawn' $(2 x+4 x) \times$ Catalpa bignonioides $(2 x)$ crosses harvested 6 weeks after pollination.

\begin{tabular}{|c|c|c|c|}
\hline \multirow{3}{*}{$\begin{array}{l}\text { Embryo } \\
\text { ploidy }\end{array}$} & \multirow{3}{*}{$\begin{array}{c}\text { Sucrose }^{z} \\
\left(\mathrm{~g} \cdot \mathrm{L}^{-1}\right)\end{array}$} & \multicolumn{2}{|c|}{ Germination (\%) } \\
\hline & & \multicolumn{2}{|c|}{$2 \%$ coconut-water } \\
\hline & & Absent & Present \\
\hline \multirow[t]{3}{*}{$3 x$} & 20 & $20.8^{y}$ & 16.7 \\
\hline & 40 & 4.2 & 4.2 \\
\hline & 80 & 0.0 & 0.0 \\
\hline Mean $^{x}$ & & $8.3 \mathrm{c}$ & $7.0 \mathrm{c}$ \\
\hline \multirow[t]{3}{*}{$4 x$} & 20 & 83.3 & 91.6 \\
\hline & 40 & 62.5 & 83.3 \\
\hline & 80 & 41.7 & 75.0 \\
\hline Mean & & $62.5 \mathrm{~b}$ & $83.3 \mathrm{a}$ \\
\hline
\end{tabular}

${ }^{\mathrm{z}}$ Schenk and Hildebrandt basal salts and vitamins, supplemented with sucrose as indicated, $0.7 \%$ agar, and $\mathrm{pH}$ adjusted to 5.7.

ySignificant linear effect for sucrose over each ploidy and coconut level $(\mathrm{n}=4)$, according to partitioned sums of squares (F value $=18.21, P$ $=0.0001)$.

xMeans $(\mathrm{n}=12)$, summed over sucrose concentration, within rows or columns followed by the same letter are not significantly different at $P$ $<0.05$ based on least significant means pairwise comparisons.

coconut-water increased germination from $62.5 \%$ to $83.3 \%$ for $4 x$ embryos. However, those embryos germinating in coconut-water had constricted, thickened roots as in Expt. 1.

Expт. 3. At 7 WAP, $3 x$ and $4 x$ embryos on SH medium with sucrose at $20 \mathrm{~g} \cdot \mathrm{L}^{-1}$ germinated across all $\mathrm{GA}_{3}$ concentrations (Table 5). Treatments were partitioned into absent $(0 \mu \mathrm{MGA})$ and present $\left(1,2\right.$, and $\left.4 \mu \mathrm{M} \mathrm{GA}_{3}\right)$ for ANOVA analysis. The presence of $\mathrm{GA}_{3}$ significantly increased germination across each ploidy level $(\mathrm{F}$ value $=2069.34, P<0.0001)$, though perhaps to a lesser extent in the $4 x$ embryos, which resulted in a significant ploidy $\times \mathrm{GA}_{3}$ interaction $(\mathrm{F}$ value $\left.=10.65, P<0.0001)\right]$.

ExpT. 4. Callus production of triploid $C$. linearis $\mathrm{x}(\times C$. tashkentensis $2 x+4 x$ ) embryos was significantly affected by WAP (F value $=7.56, P=0.0004)$, with 4,5 , or 6 WAP resulting in high callus production (Table 6 ). Weeks after pollination did not effect germination percent (F value $=0.97, P=0.4402)$ in part due to low germination across three of the harvest dates $(4,5$, or 6 WAP). Excised embryos at 7 WAP were visually smaller than those at 6 WAP, and appeared flat and desiccated.

\section{Discussion}

Oryzalin treatment of apical meristems of $\times C$. tashkentensis 'Pink Dawn' was effective at inducing tetraploid cells, albeit in the form of mixoploid or chimeric shoots (Fig. 1). The prevalence of mixoploids over non-chimeric tetraploids in our treatments is a typical response when inducing polyploidy. In Solanum L. species, treating excised apical meristems of various dihaploid $\times$ diploid crosses and parental taxa with $28.8 \mu \mathrm{m}$ oryzalin in vitro resulted in low tetraploid conversion rates $(0$ to $12 \%$, taxa dependent) and a preponderance of mixoploid plantlets (Chauvin et al., 2003). Väinölä (2000) exposed microshoots of three different Rhododendron L. taxa to either 30 or $150 \mu \mathrm{m}$ oryzalin for 24 or $48 \mathrm{~h}$. The combined oryzalin treatments resulted in $37 \%$ mixoploids and $8 \%$ tetraploids, which is similar to the $34 \%$ and $2 \%$ for mixoploids and tetraploids, respectively, reported herein. Optimal treatments for inducing polyploid shoots should approach $50 \%$ mortality (Sanford, 1983). Our efficacy data demonstrate
Table 5. Effect of $\mathrm{GA}_{3}$ on germination of $\times$ Chitalpa embryos from $\times$ Chitalpa tashkentensis 'Pink Dawn' $(2 x+4 x) \times$ Catalpa bignonioides $(2 x)$ crosses harvested 7 weeks after pollination (WAP).

\begin{tabular}{lccc}
\hline $\mathrm{GA}_{3}{ }^{\mathrm{z}}$ & \multicolumn{3}{c}{ Germination $(\%)$} \\
\cline { 2 - 4 }$(\mu \mathrm{M})$ & $3 x$ & $4 x$ & Mean $^{\mathrm{x}}$ \\
\hline 0 & $11.1^{\mathrm{y}}$ & 30.6 & $20.8 \mathrm{~b}$ \\
1 & 100.0 & 100.0 & \\
2 & 100.0 & 100.0 & $99.1 \mathrm{a}$ \\
4 & 97.2 & 97.2 & \\
\hline
\end{tabular}

${ }^{2}$ Schenk and Hildebrandt basal salts and vitamins supplemented with $\mathrm{GA}_{3}$ as indicated, sucrose at $20 \mathrm{~g} \cdot \mathrm{L}^{-1}, 0.7 \%$ agar, and $\mathrm{pH}$ adjusted to 5.7 . yMeans presented as $\mathrm{GA}_{3}$ treatment partitioned as absence $(\mathrm{n}=12)$ or presence $(\mathrm{n}=36)$ of $\mathrm{GA}_{3}(0$ vs. 1,2 , or $4 \mu \mathrm{m}$, respectively) across ploidy levels $(\mathrm{F}$ value $=2069, P<0.0001)$

${ }^{x}$ Means $(\mathrm{n}=6)$ within a ploidy.

Table 6. Callus production and embryo germination for triploid $(3 x)$ $\times$ Chitalpa embryos from Chilopsis linearis $(2 x) \times \times$ Chitalpa tashkentensis 'Pink Dawn' $(2 x+4 x)$ crosses harvested 3, 4, 5, 6, or 7 weeks after pollination (WAP).

\begin{tabular}{llc}
\hline WAP $^{\mathrm{z}}$ & Callus $(\%)$ & Germination $(\%)$ \\
\hline 3 & $47.9 \mathrm{bcy}$ & $0.0^{\mathrm{x}}$ \\
4 & $89.7 \mathrm{a}$ & 2.1 \\
5 & $87.5 \mathrm{a}$ & 2.1 \\
6 & $66.7 \mathrm{ab}$ & 4.2 \\
7 & $25.0 \mathrm{c}$ & 0.0
\end{tabular}

zSchenk and Hildebrandt basal salts and vitamins supplemented with sucrose at $20 \mathrm{~g} \cdot \mathrm{L}^{-1}, 0.7 \%$ agar, $1 \mu \mathrm{M} \mathrm{GA}, \mathrm{pH}$ adjusted to 5.7 , and harvested when indicated.

yMeans $(n=6)$ followed by the same letter are not significantly different according to Fisher's protected least significance difference at $\alpha=0.05$.

'WAP had no significant effect on germination $(\mathrm{F}$ value $=0.97, P=$ 0.4402).

that as shoot mortality increases up to the 24-h treatment, the remaining shoots are predominantly mixoploid with a few nonchimeric tetraploids (Fig. 1). Since our shoot mortality in the 24-h treatment was approaching $40 \%$, a treatment $>24$ h may lead to increased incidence of tetraploid shoots. The prevalence of mixoploids can be attributed to gradations in mitotic activity within the apical meristem (Francis, 1997) such that some cells are cell-cycling faster than others and thus more susceptible to inhibition by oryzalin. Longer oryzalin treatments would ensure that a greater percentage of cells are exposed during cell-cycling. Furthermore, unless each apical initial cell in the meristem is doubled, the resulting shoot will be chimeric, displaying both diploid and tetraploid sectors (sectorial or mericlinal chimera). The ploidy level of leaves can be used as a surrogate for the ploidy level of axillary buds, since both share a common lineage with meristematic cells in the peripheral zone of the apical meristem (Tian and Marcotrigiano, 1994). Removing apical meristems forces axillary buds to break, and in a sectorial cytochimera, may result in axillary shoots comprised primarily of tetraploid cells. After two rounds of cutting back shoots and ploidy sampling, we were able to stabilize four non-chimeric tetraploids and two cytochimeras. Previous induction studies with rose (Kermani et al., 2003) and potato (Chauvin et al., 2003) have likewise required rescreening and propagation for stabilizing induced tetraploids.

Flow cytometry of leaf tissue of $\times$ Chitalpa (Fig. 2A-D) permitted efficient screening and rescreening of ploidy levels. The flexibility of flow cytometry was further demonstrated by 
identification of the chimeral state of stamens and petal tissues in our cytochimeras. Since angiosperm stamens typically are comprised of two histogenic layers, an L-I epidermis and L-II gamete-producing internal layers (Goldberg et al., 1993), it was assumed that our stable cytochimeras consisted of a $2 x$ L-I epidermis and $4 x$ L-II or LII-LIII histogenic layers.

Pollen grains in Catalpa spp. and C. linearis are united into tetrads with coarsely reticulate areoles (Gentry and Tomb, 1979). Both parental taxa exhibited high pollen viability and germination, although pollen viability may have been overestimated by the acetocarmine stain (Table 1 ). In diploid $\times$ Chitalpa, the pollen grains form highly variable polyads, but rarely, if ever, tetrads (Elias and Wisura, 1991), indicating a high degree of sterility, which we confirmed using pollen viability and germination tests (Table 1). Cytochimera $\times$ Chitalpa produced well-formed tetrads and pollen grains that stained and germinated in greater percentages than diploid $\times$ Chitalpa and greater than or equal to the parent taxa, $C$. bignonioides and $C$. linearis (Table 1). Because our non-chimeric allotetraploids flowered sparsely, the cytochimeras became important for crossing studies, since for breeding purposes, they behaved primarily as allotetraploids (Pratt, 1983).

Concomitant with restoration of pollen viability was female fertility in the induced cytochimera and tetraploid $\times C$. tashkentensis. As suggested previously (Elias and Wisura, 1991), diploid $\times$ C. tashkentenis 'Pink Dawn' is completely female sterile, which was confirmed by selfing and crossing with $C$. bignonioides and C. linearis 'Bubba' (Table 2). Cytochimeric $\times$ C. tashkentensis were selfed successfully and resulted in moderate seed production and germination. For viable crosses, fruit set never exceeded $25 \%$ of the flowers pollinated. In hand-pollination experiments with Catalpa speciosa (Ward. ex Barn.) Ward. ex Engelm., successful pollinations decline after the first four flowers are successfully pollinated, with the earliest flowers having the greatest fruit set and later flowers functioning as males only (Stephenson, 1979). Thus, in C. speciosa and perhaps C. linearis and fertile $\times$ Chitalpa, fruit set is not limited by successful pollinations but appears to be regulated by the plant (Stephenson, 1980). Furthermore, Stephenson (1982) found that fruit set in natural populations of $C$. speciosa over a 2-year period varied from $7 \%$ and $20 \%$, which is within our fruit set percentages for controlled crosses in the greenhouse for the various successful crosses. Both Catalpa spp. and C. linearis are self-incompatible (SI) (Petersen et al., 1982; Stephenson and Thomas, 1977). Late-acting self-incompatibility (LSI), a type of gametophytic self-incompatibility (GSI), is common in the Bignoniaceae (Gibbs and Bianchi, 1999), and GSI is often overcome upon induction of polyploidy (Lewis, 1947). Although it is not possible to separate self-sterility from SI reaction in our original diploid $\times C$. tashkentensis, the appearance of self-fertility in the induced allotetraploid $\times$ Chitalpa raises the question of overcoming SI in tetraploid forms of Catalpa spp. and $C$. linearis.

Cytochimeric $\times C$. tashkentensis were crossed successfully with $C$. bignonioides, with fruit set similar to that from selfing, but twice as much seed per fruit ( 50.5 vs. 94.1 seeds) developed and germination was only $19.5 \%$. The recovery of triploids in this cross demonstrates lack of a triploid block when a tetraploid female is pollinated by a diploid male, as predicted by the endosperm balance number theory (EBN) (Johnston et al., 1980). Pollination of cytochimeric $\times C$. tashkentensis with $C$. linearis 'Bubba' resulted in extremely poor fruit set with 60.0 seeds per fruit that were not viable. This may represent a prefertilization gametophytic incompatibility (e.g., failure of pollen germination and pollen tube growth). When $C$. linearis 'Bubba' or 'Burgundy Lace' were pollinated with cytochimeric and tetraploid $\times C$. tashkentensis, fruit set ranged from $12.8 \%$ to $21.1 \%$ and average seed from 28.8 to 112.3 but again, no viable triploid seed was produced, as predicted by EBN. Seedlings recovered from these crosses were all diploid, evidence that triploid embryos triggered fruit set and maturation before aborting. This allowed for the recovery of diploid progeny that were the result of the rare production of viable pollen with a haploid chromosome number from the cytochimera and tetraploid plants (Sanford, 1983). Development of stamens involves contributions of all three histogenic layers (Dermen and Stewart, 1973), but sporogenesis originates and the anther sac is derived from the L-II layer. Chimeric plants are not completely stable, with frequent replacement or displacement of histogenic layers occurring from cells derived from adjacent layers. Our cytochimeric $\times C$. tashkentenis must have produced rare, viable haploid pollen from displacement of the tetraploid L-II with a diploid cell from L-I or L-III. Diploid pollen produced by the tetraploid L-II fertilized haploid eggs in C. linearis, forming triploid embryos which trigger seed set and fruit maturation, but which later abort, leaving only the rare, diploid embryo to develop. In the original sterile diploid $\times C$. tashkentenis 'Pink Dawn', viable pollen grains are only occasionally observed (Table 1 ). The one diploid seedling that resulted from the seed of $C$. linearis 'Bubba' crossed with our non-chimeric tetraploid, again maybe the result of the rare production of haploid pollen grains from the induced tetraploid male parent.

In the present investigation, fruit of $\times C$. tashkentensis and $C$. linearis grew rapidly in length the first 7 WAP, then leveled off until maturation 14 or 15 WAP. Fruits of $C$. speciosa accumulate dry matter and proteins slowly during the first 6 WAP, then rapidly for the next several weeks (Stephenson, 1980). Rapid cell division and elongation in $\times$ Chitalpa, and the transition to dry matter and protein accumulation in C. speciosa, appear to coincide with growth of the embryos, which was first noted 6 WAP. Ovule and embryo culture experiments one through three utilized selfed cytochimeric $\times C$. tashkentenis and crosses with diploid $C$. bignonioides, a cross that was subsequently shown to be viable and led to triploid progeny (Fig. 2C).

Previous research has demonstrated suitability of $\mathrm{SH}$ basal salts for micropropagation of C. bignonioides (Wysokinska and Swiatek, 1989) and C. ovata G. Don. (Lisowska and Wysokinska, 2000). In Expt. 1, tetraploid and triploid ovules harvested prior to 5 WAP failed to germinate in our SH medium and tissue culture system. In ovule culture may be inappropriate for heterotrophic embryos embedded in excess ovule tissue, which may impede uptake and translocation of vitamins and nutrients from the medium, although embryo germination as high as $30 \%$ was observed. Five WAP for tetraploids and 6 WAP for triploids, in ovule embryos may have developed sufficiently on the plant to reach a developmental stage responsive to lower sucrose concentrations. There was a benefit of higher sucrose for tetraploid ovules 5 WAP, but not at 6 WAP, and may also reflect increased development of in ovule embryos, with higher osmolarity beneficial at a younger developmental stage (Bridgen, 1994; Sharma et al., 1996).

In Expt. 2, embryos were excised 6 WAP. High sucrose concentrations inhibited germination of excised embryos of $\times$ Chitalpa and have been known to prevent precocious germination of embryos in vitro (Sharma et al., 1996). Although coconut-water had no effect on intact ovules, for excised embryos there was a slight increase in germination for tetraploid embryos but no ef- 
fect on triploids. Germination in coconut-water, or in sucrose at $80 \mathrm{~g} \cdot \mathrm{L}^{-1}$, led to constricted, thickened roots, possibly an effect of higher osmolarity.

In Expt. 3, excised embryos at 7 WAP were treated with $\mathrm{GA}_{3}$, a hormone that promotes germination in tissue culture (Sharma et al., 1996). The presence of $\mathrm{GA}_{3}$ from 1 to $4 \mu \mathrm{M}$ significantly increased germination for triploids and tetraploids, indicating harvesting embryos, independent of the ploidy level, at 7 WAP could lead to high germination rates in vitro. These first three experiments demonstrated that germination of embryos from crosses of $\times C$. tashkentenis $(2 x+4 x) \times C$. bignonioides $(2 x)$ are possible as early 5 WAP for tetraploids, and 6 WAP for triploids, with high germination by 7 WAP for both crosses. Seeds harvested from this cross germinated at $19.5 \%$, indicating a triploid block does not exist in this direction with these parents. The reciprocal cross, $C$. bignonioides $(2 x) \times \times C$. tashkentenis $(2 x+4 x)$, was not performed due to a lack of flowering $C$. bignonioides at the MHCREC.

Early observations from pollination experiments indicated that a triploid block may be present, as predicted by EBN theory, when diploid $C$. linearis is pollinated by tetraploid $\times C$. tashkentensis. Using the media optimized for germination of viable tetraploid and triploid embryos, we investigated timing of harvest of $C$. linearis fruit, with the hypothesis that our previous optimized SH medium was sufficient to rescue triploid embryos with poor endosperm development as a result of violating the 2 maternal : 1 paternal genome ratio in the endosperm (Expt. 4). We were able to recover triploid embryos at 4, 5, and 6 WAP, but germination rate was never $>5 \%$. Abundant callus was produced up to 6 WAP, facilitating future studies to investigate somatic embryogenesis and shoot organogenesis from triploid callus as an alternative to rescuing intact triploid embryos. By 7 WAP, the embryos appeared to be degenerating, with significantly lower callus production and no germination was induced. Maximum embryo development, and hence optimal timing for excising embryos, of $C$. linearis $(2 x) \mathrm{x} \times C$. tashkentenis $(2 x+4 x)$ was after 3 WAP but before 7 WAP. Lack of seed germination from mature fruit of this cross, combined with observations of degenerate embryos, indicates a triploid block exists in this direction. Late abortion of embryos (i.e., embryos beyond the torpedo stage) is often the result of nutritional imbalances or starvation of the embryo from poor endosperm development (Mont et al., 1993), which itself is a result of violation of EBN (Carputo et al., 1999). Although coconut-water and sucrose concentrations $>20 \mathrm{~g} \cdot \mathrm{L}^{-1}$ were not appropriate for in ovule embryos and excised embryos from viable triploid crosses, they may be appropriate as a source of unreduced organic nitrogen or increased osmolarity, respectively, for culturing embryos with poor endosperm development from triploid crosses that violate EBN (Sharma et al., 1996). Further studies will be needed to optimize our media for increasing germination of embryos of $\times$ Chitalpa earlier than 7 WAP in crosses in the direction of the triploid block.

Results herein demonstrate the feasibility of inducing polyploidy in vegetative meristems of $\times C$. tashkentenis and isolation and recovery of stable, allotetraploid breeding clones. Discovery of self-fertility in allotetraploid $\times$ Chitalpa allows for production of advanced generations with increased recombination between genomes of Catalpa spp. and C. linearis. Introgression of desired traits from Catalpa spp. is possible due to absence of a triploid block when crossing with allotetraploid $\times$ Chitalpa. Failure of crosses between allotetraploid $\times C$.tashkentenis and $C$. linearis in either direction, either due to pollen-pistil interactions or a triploid block is an important note. Embryo rescue of these crosses were successful, although methods for increasing the cross successes are needed to increase the number of embryos for evaluation. Use of $C$. linearis as a breeding parent is desirable owing to superior flower colors, foliage, and plant habit, and tolerances to high temperatures and drought available within germplasm of C. linearis. Integration of these traits can lead to development of novel, improved selections of $\times$ Chitalpa that increases the palette of small trees tolerant of wide extremes in growing conditions present in urban environments.

\section{Literature Cited}

Bajer, A.S. and J. Molè-Bajer. 1986. Drugs with colchicine-like effects that specifically disassemble plant but not animal microtubules. Ann. New York Acad. Sci. 466:767-784.

Bartels, P.G. and J.L. Hilton. 1973. Comparison of trifluralin, oryzalin, pronamide, propham, and colchicine treatments on microtubules. Pesticide Biochem. Physiol. 3:462-472.

Beyl, C.A. 2000. Getting started with tissue culture-media preparation, sterile technique, and laboratory equipment, p. 21-38. In: R.N. Trigiano and D.J. Gray (eds.). Plant tissue culture concepts and laboratory excercises. CRC Press, Boca Raton, Fla.

Bridgen, M.P. 1994. A review of plant embryo culture. HortScience 29:1243-1246.

Brewbaker, J.L. and B.H. Kwack. 1963. The essential role of calcium ion in pollen germination and pollen tube growth. Amer. J. Bot. 50:859-865.

Brubaker, C.L., A.H.D. Brown, J.M. Stewart, M.J. Kilby, and J.P. Grace. 1999. Production of fertile hybrid germplasm with diploid Australian Gossypium species for cotton improvement. Euphytica 108:199-213.

Carputo, D., L. Monti, J.E. Werner, and L. Frusciante. 1999. Uses and usefulness of endosperm balance number. Theor. Appl. Genet. 98:478-484.

Chauvin, J.E., C. Souchet, J.P. Dantec, and D. Ellissèche. 2003. Chromosome doubling of $2 \mathrm{x}$ Solanum species by oryzalin: Method development and comparison with spontaneous chromosome doubling in vitro. Plant Cell Tissue Organ Cult. 73:65-73.

Cole, P. and B. Melton. 1986. Self- and cross-compatibility relationships among genotypes and between ploidy of the rose. J. Amer. Soc. Hort. Sci. 111:122-125.

de Laat, A.M.M., W. Göhde, and M.J.D.C. Vogelzang. 1987. Determination of ploidy of single plants and plant populations by flow cytometry. Plant Breeding 99:303-307.

Dermen, H. and R.N. Stewart. 1973. Ontogenetic study of floral organs of peach (Prunus persica) utilizing cytochimeral plants. Amer. J. Bot. 60:283-291.

Doležel, J. 1991. Flow cytometric analysis of nuclear DNA content in higher plants. Phytochem. Analysis 2:143-154.

Doležel, J., J. Greilhuber, S. Lucretti, A. Meister, M.A. Lysák, L. Nardi, and R. Obermayer. 1998. Plant genome size estimation by flow cytometry: Inter-laboratory comparison. Ann. Bot. 82:17-26.

Elias, T.S. and W. Wisura. 1991. ×Chitalpa tashkentensis (Bignoniaceae), an intergeneric hybrid of ornamental value. Baileya 23:139-144.

Francis, D. 1997. The stem cell concept applied to shoot meristems of higher plants, p. 59-73. In: C.S. Potten (ed.). Stem cells. Academic Press, San Diego.

Galbraith, D.W., K.R. Harkins, J.M. Maddox, N.M. Ayres, D.P. Sharma, and E. Firoozabady. 1983. Rapid flow cytometric analysis of the cell cycle in intact plant tissues. Science 220:1049-1051.

Gentry, A.H. and S. Tomb. 1979. Taxonomic implications of Bignoniaceae palynology. Ann. Missouri Bot. Garden 66:756-777.

Gibbs, P.E. and M.B. Bianchi. 1999. Does late-acting self-incompatibility (LSI) show family clustering? Two more species of Bignoniaceae with LSI: Dolichandra cynanchoides and Tabebuia nodosa. Ann. Bot. 84:449-457. 
Goldberg, R.B., T.P. Beals, and P.M. Sanders. 1993. Anther development: Basic principles and practical applications. Plant Cell 5:1217-1229.

Goldblatt,P. and A.H. Gentry. 1979. Cytology of Bignoniaceae. Botaniska Notiser 132:475-482.

Gottschalk, W. 1978. Open problems in polyploidy research. Nucleus 21:99-112.

Hadley, H.H. and S.J. Openshaw. 1980. Interspecific and intergeneric hybridization, p. 133-159. In: W.R. Fehr and H.H. Hadley (eds.). Hybridization of crop plants. Crop Sci. Soc. Amer., Madison, Wis.

Henrickson, J. 1985. A taxonomic revision of Chilopsis (Bignoniaceae). Aliso 11:179-197.

Jackson, S.A. and R.E. Hanneman, Jr. 1999. Crossability between cultivated and wild tuber- and non-tuber-bearing solanums. Euphytica 109:51-67.

Jan, C.C. and J.M. Chandler. 1989. Sunflower interspecific hybrids and amphiploids of Helianthus annuus $\times$ H. bolanderi. Crop Sci. 29:643-646.

Johnston, S.A., T.P.M. den Nijs, S.J. Peloquin, and R.E. Hanneman, Jr. 1980. The significance of genic balance to endosperm development in interspecific crosses. Theor. Appl. Genet. 57:5-9.

Jones, D.F. and W.O. Filley. 1920. Teas' hybrid catalpa. J. Hered. 11:16-24.

Kermani, M.J., V. Sarasan, A.V. Roberts, K. Yokoya, J. Wentworth, and V.K. Sieber. 2003. Oryzalin-induced chromosome doubling in Rosa and its effect on plant morphology and pollen viability. Theor. Appl. Genet. 107:1195-1200.

Levin, D.A. 2002. The role of chromosomal change in plant evolution. Oxford Univ. Press, Oxford, U.K.

Lewis, D. 1947. Competition and dominance of incompatibility alleles in diploid pollen. Heredity 1:85-108.

Lisowska, K. and H. Wysokinska. 2000. In vitro propagation of Catalpa ovata G. Don. Plant Cell Tissue Organ Cult. 60:171-176.

Ma, Y., D.H. Byrne, and J. Chen. 1997. Amphidiploid induction from diploid rose interspecific hybrids. HortScience 32:292-295.

Mont, J., M. Iwanaga, G. Orjeda, and K. Watanabe. 1993. Abortion and determination of stages for embryo rescue in crosses between sweetpotato, Ipomoea batatas Lam. $(2 \mathrm{n}=6 \mathrm{x}=90)$ and its wild relative, $I$. trifida (H.B.K.) G. Don. $(2 \mathrm{n}=2 \mathrm{x}=30)$. Sexual Plant Reproduction 6:176-182.

Morejohn, L.C., T.E. Bureau, J. Molè-Bajer,A.S. Bajer, and D.E. Fosket. 1987. Oryzalin, a dinitroaniline herbicide, binds to plant tubulin and inhibits microtubule polymerization in vitro. Planta 172:252-264.

Newcombe, F.C. 1922. Significance of the behavior of sensitive stigmas. Amer. J. Bot. 9:99-120.

Petersen, C., J.H. Brown, and A. Kodric-Brown. 1982. An experimental study of floral display and fruit set in Chilopsis linearis (Bignoniaceae). Oecologia 55:7-11.

Pratt, C. 1983. Somatic selection and chimeras, p. 172-185. In: J.N.
Moore and J. Janick (eds.). Methods in fruit breeding. Purdue Univ. Press, West Lafayette, Ind.

Ramulu, K.S., H.A. Verhoeven, and P. Dijkhuis. 1991. Mitotic blocking, micronucleation, and chromosome doubling by oryzalin, amiprophosmethyl, and colchicine in potato. Protoplasma 160:65-71.

Rieseberg, L.H. and S.E. Carney. 1998. Plant hybridization. New Phytol. 140: 599-624.

Rusanov, N.F. 1964. On the intergeneric hybrids of Catalpa and Chilopsis. Biulleten Glavnogo botanicheskogo sada. Akademia nauk SSSR 55:44-47 (In Russian).

Rusanov, N.F. 1971. Intergeneric hybrids of Catalpa with Chilopsis and their significance for understanding phylogeny. Introduction and acclimatization of plants (Tashkent) 8:50-58 (In Russian).

Sanford, J.C. 1983. Ploidy manipulations, p. 100-123. In: J.N. Moore and J. Janick (eds.). Methods in fruit breeding. Purdue Univ. Press, West Lafayette, Ind.

Sargent, C.S. 1889. A hybrid catalpa. Garden For. 2:303-305.

Sharma, D.R., R. Kaur, and K. Kumar. 1996. Embryo rescue in plants - A review. Euphytica 89:325-337.

Smith, E.C. 1941. Chromosome behavior in Catalpa hybrida Spaeth. J. Arnold Arboretum 22:219-221.

Stephenson,A.G. 1979. An evolutionary examination of the floral display of Catalpa speciosa (Bignoniaceae). Evolution 33:1200-1209.

Stephenson, A.G. 1980. Fruit set, herbivory, fruit reduction, and the fruiting strategy of Catalpa speciosa (Bignoniaceae). Ecology 61:57-64.

Stephenson,A.G. 1982. When does outcossing occur in a mass-flowering plant? Evolution 36:762-767.

Stephenson, A.G. and W.W. Thomas. 1977. Diurnal and nocturnal pollination of Catalpa speciosa (Bignoniaceae). Syst. Bot. 2:191-198.

Tian, H.-C. and M. Marcotrigiano. 1994. Cell-layer interactions influence the number and position of lateral shoot meristems in nicotiana. Dev. Biol. 162:579-589.

Tosca, A., R. Pandolfi, S. Citterio, A. Fasoli, and S. Sgorbati. 1995. Determination by flow cytometry of the chromosome doubling capacity of colchicine and oryzalin in gynogenetic haploids of gerbera. Plant Cell Rpt. 14:455-458.

Upadhyaya, M.K. and L.D. Noodèn. 1977. Mode of dinitroaniline herbicide action I. Analysis of the colchicine-like effects of dinitroaniline herbicides. Plant Cell Physiol. 18:1319-1330.

Upadhyaya, M.K. and L.D. Noodèn. 1980. Mode of dinitroaniline herbicide action II. Characterization of $\left[{ }^{14} \mathrm{C}\right]$ oryzalin uptake and binding. Plant Physiol. 66:1048-1052.

Väinölä,A. 2000. Polyploidization and early screening of Rhododendron hybrids. Euphytica 112:239-244.

Vaughn, K.C. and L.P. Lehnen, Jr. 1991. Mitotic disrupter herbicides. Weed Sci. 39:450-457.

Wysokinska, H. and L. Swiatek. 1989. Micropropagation of Catalpa bignonioides Walt. through tissue cultures. Acta Societatis Botanicorum Poloniae 58:185-198. 